\title{
Evaluation of Forward Osmosis as a Pretreatment Process for Multi Stage Flash Seawater Desalination
}

Mshael S. Thabit ${ }^{a}$, Alaa H. Hawarib, ${ }^{\text {, }}$, Mhd. Hafez Ammar ${ }^{b}$, Syed Zaidic, Guillermo Zaragozad $^{\mathrm{d}}$, Ali Altaee ${ }^{\mathrm{e}}{ }^{*}$

aEnvironmental Engineering Master Program (EEMP), Qatar University, P.O. Box 2713, Doha, Qatar.

bDepartment of Civil and Architectural Engineering, Qatar University, P.O. Box 2713, Doha, Qatar.

'Centre for Advanced Materials, Qatar University, P.O. Box 2713, Doha, Qatar.

dCIEMAT-Plataforma Solar de Almería, Ctra. de Senés s/n, 04200 Tabernas, Almería, Spain.

eSchool of Civil and Environmental Engineering, University of Technology in Sydney, 15 Broadway, Ultimo, NSW 2007, Australia.

${ }^{*}$ Corresponding authors:

Dr. Alaa H. Hawari; Tel.: +(974) 3393-1555; Fax: +(974) 4403-4172. E-mail address: a.hawari@qu.edu.qa,

Dr. Ali Altaee; Tel.: +(614) 2060-6500, Email address: Ali.altaee@uts.edu.au; 
48 The present study evaluates the feasibility of applying forward osmosis (FO) process for

49 the pretreatment of feed solution to a Multi Stage Flash (MSF) desalination plant. For the

50 first time, real brine reject and real seawater were used as the draw solution and the feed

51 solution, respectively in the FO process. The FO pretreatment is expected to dilute the

52 brine reject and reduce the concentration of divalent ions, which are responsible for scale

53 formation on the surface of heat exchanger in the MSF evaporator unit. The FO

54 experiments were performed at different draw solution temperatures ranging between 25

$55-40^{\circ} \mathrm{C}$, different draw and feed solutions flowrates and different membrane orientations.

56 A maximum average membrane flux of $22.3 \mathrm{~L} / \mathrm{m}^{2} . \mathrm{h}$ was reported at a draw solution

57 temperature of $40^{\circ} \mathrm{C}$ and 0.8 and 2.0 LPM flow rate of draw and feed solutions,

58 respectively. The experimental results also revealed the process sensitivity to the feed

59 solution temperature. It was found that the average membrane flux in the FO process

60 operating at 0.8 and 2 LPM draw and feed solution flow rates, respectively was 16.9

$61 \mathrm{~L} / \mathrm{m}^{2} . h$ at $25^{\circ} \mathrm{C}$ brine temperature but increased to $22.3 \mathrm{~L} / \mathrm{m}^{2} . h$ at $40^{\circ} \mathrm{C}$ brine temperature.

62 These membrane fluxes resulted in $3 \%$ and $8.5 \%$ dilution of the draw solution at $25^{\circ} \mathrm{C}$

63 and $40^{\circ} \mathrm{C}$ temperatures, respectively. The average membrane flux in the FO mode was

64 equal to that in the PRO mode at low flow rates but it was lower than that in the PRO

65 mode at high flow rates of the feed and draw solutions. The outcomes of the study are

66 very promising with regard to membrane flux and dilution of draw solution.

67

68 Keywords: Forward Osmosis (FO); Multi Stage flash (MSF); Pretreatment; Scaling; 69 Membrane flux. 


\section{Introduction}

Thermal desalination processes such as multi stage flash (MSF) and multi effect distillation (MED) demonstrated a high performance in a harsh environment without the requirements for seawater pretreatment. Conventionally, the top brine temperatures (TBT- the operating temperature in thermal desalination plant) in the MSF (operating in brine recycle mode) and MED are $65^{\circ} \mathrm{C}$ and $112^{\circ} \mathrm{C}$, respectively. These temperatures would achieve a recovery rate equal to $30 \%$ in both technologies [1-3]. However, these processes experience a major drawback represented by scale formation and deposition on the surface of heat transfer tubes. Scale formation reduces the heat transfer efficiency of the heat exchangers and adversely impact the performance of the thermal plant [1-4]. Alkaline scales, mainly $\mathrm{CaCO}_{3}$, were reported in MED plants while non-alkaline scales, such as $\mathrm{MgSO}_{4}$ and $\mathrm{CaSO}_{4}$, were the main scale formations in the MSF plants [3]. The main strategies for scale minimization and removal in thermal plants are the use of antiscalants and periodic cleaning. Technically, these strategies are not effective in preventing scale deposition that builds up over time [2,5-8]. Alternatively, unconventional processes such as pretreatment using Nanofiltration (NF) membrane was proposed for the removal of scale ions from the feed solution to thermal plants $[9,10]$. Integrating NF with thermal desalination demonstrated a high efficiency in the removal of divalent ions, such as $\mathrm{Ca}^{2+}, \mathrm{Mg}^{2+}$ and $\mathrm{SO}_{4}{ }^{-2}$, from seawater and allowed thermal plants to operate at elevated top brine temperatures [11]. An experimental work by Hasan et al. [10] demonstrated the advantage of NF pretreatment of seawater for the removal of scale ions and feasibility to increase the TBT of the MSF plant to $130^{\circ} \mathrm{C}$. Operating at a TBT equal to $130^{\circ} \mathrm{C}$ increased the recovery rate in the MSF plant and produced a gained output ratio (GOR) of 13. Despite the successful application of NF process for pretreatment of seawater, economically the process was unfeasible due to the high-energy cost [12-14].

The specific power consumption in the NF process was $1 \mathrm{kWh} / \mathrm{m}^{3}$ when operating at a $65 \%$ recovery rate which is considered relatively high for an economic desalination process $[15,16]$.

A previous study investigated the feasibility of FO pretreatment of feed solution to the MSF plant [17]. Brine reject was used as the draw solution while seawater was the feed solution. The study revealed the potential of the FO process to reduce the concentration 
105 of divalent ions in the brine reject [17]. At a $32 \%$ recovery rate, $62 \%$ reduction in the 106 concentration of $\mathrm{Ca}^{2+}, \mathrm{Mg}^{2+}$ and $\mathrm{SO}_{4}{ }^{2-}$ ions was achieved by the $\mathrm{FO}$ process. Moreover, 107 the feasibility of the FO process combined to MSF plant is approved to reduce the 108 concentration of divalent ions in the feed solution at $130{ }^{\circ} \mathrm{C}[15]$. The estimated water 109 flux for $45 \mathrm{~g} / \mathrm{L}$ seawater salinity was in the range of $4 \mathrm{~L} / \mathrm{m}^{2} . \mathrm{h}$ to $9.6 \mathrm{~L} / \mathrm{m}^{2} \mathrm{~h}$ depending on 110 the recovery rate of the FO process. For $45 \mathrm{~g} / \mathrm{L}$ seawater salinity and $16 \%$ FO recovery

111 rate, the concentration of divalent ions in the draw solution decreased by $13 \%$ after the

112 FO treatment. The corresponding value for $32 \%$ FO recovery rate was $23.5 \%$ reduction in

113 the concentration of divalent ions [15]. Unlike the NF process, the driving force in the FO

114 process is the osmotic pressure gradient across the FO membrane instead of the hydraulic

115 pressure $[17,18]$. Therefore, the cost of such pretreatment process is expected to be lower

116 than that of the NF process.

117 Previous FO studies on the pretreatment of feed solution to the MSF plant were

118 theoretical and there is no experimental data, yet to proof the concept. Experimental data, 119 therefore, are essential to demonstrate the feasibility of the FO-MSF system for seawater

120 desalination. In this study, we experimentally investigated the feasibility of FO process

121 for the treatment of the feed solution to the MSF plant. Real MSF brine reject and

122 seawater, the draw and feed solution, respectively, were collected from a thermal 123 desalination plant in Doha City, Qatar. The study investigated the impact of different 124 operating parameters on the performance of the FO process. Concentration of divalent 125 ions in the brine reject was measured before and after the FO process to determine the 126 dilution ratio. In the FO process a brine reject (BR) collected from a MSF thermal desalination plant in Qatar was used as the draw solution (DS) while the feed solution (FS) was seawater collected from the west bay in Qatar. The characteristics and composition of the DS and 
the FS in terms of cation and anion concentrations, total dissolved solids (TDS), conductivity, $\mathrm{pH}$ and turbidity are illustrated in Table 1.

Table 1: Characteristics of seawater and brine reject of MSF

\begin{tabular}{|c|c|c|c|}
\hline & $\begin{array}{l}\text { FS } \\
\text { (SW) }\end{array}$ & $\begin{array}{l}\text { DS } \\
\text { (BR) }\end{array}$ & Method \\
\hline $\mathrm{Cl}^{-}(\mathbf{p p m})$ & 22183.7 & 35377.9 & \multirow{3}{*}{$\begin{array}{l}\text { APHA } 4110 \text { DETERMINATION OF ANIONS } \\
\text { BY ION CHROMATOGRAPHY } \\
\text { Equipment: Metrohm } 850 \text { Professional IC }\end{array}$} \\
\hline $\mathrm{Br}^{-}(\mathbf{p p m})$ & 74.93 & 118.79 & \\
\hline $\mathrm{SO}_{4}{ }^{2-}(\mathrm{ppm})$ & 3153.6 & 5041.5 & \\
\hline $\mathrm{Na}^{+}(\mathbf{p p m})$ & 12952.6 & 20993.4 & \multirow{4}{*}{$\begin{array}{l}\text { APHA } 3120 \text { METALS BY PLASMA } \\
\text { EMISSION SPECTROSCOPY } \\
\begin{array}{l}\text { Equipment: iCAP } \quad 6500-\text { ICP-OES } \\
\text { Spectrometer (Thermo Scientific) }\end{array}\end{array}$} \\
\hline $\mathbf{K}^{+}(\mathbf{p p m})$ & 458.7 & 739.7 & \\
\hline $\mathrm{Ca}^{2+}(\mathbf{p p m})$ & 485.8 & 725.4 & \\
\hline $\mathrm{Mg}^{2+}(\mathbf{p p m})$ & 1535.0 & 2504.8 & \\
\hline TDS (ppm) & 43474 & 81492 & $\begin{array}{l}\text { APHA } 2540 \mathrm{C} \text {. Total Dissolved Solids Dried at } \\
180^{\circ} \mathrm{C}\end{array}$ \\
\hline $\begin{array}{l}\text { Conductivity } \\
(\mu s / \mathrm{cm})\end{array}$ & 60750 & 93650 & APHA 2510 B. Conductivity \\
\hline pH & 8.40 & 9.07 & APHA 4500-H+ B. Electrometric Method \\
\hline $\begin{array}{l}\text { Turbidity } \\
\text { (NTU) }\end{array}$ & 1.45 & 0.35 & APHA 2130 B. Nephelometric Method \\
\hline
\end{tabular}

\subsection{FO membrane}

141 In this study, a flat sheet Thin Film Composite (TFC) FO membrane made by HTI

142 (USA). According to the manufacturer the membrane can tolerate temperatures up to 40

$143{ }^{\circ} \mathrm{C}$ and has a rejection rate for sodium chloride ions of $90 \%$. The membrane was placed

144 inside the FO cell and washed for 30 minutes with distilled water for pre-conditioning 
and removal of any impurities from the surface. A $1 \mathrm{~mm}$ Sepa CF high fouling spacer ( 8 $\mathrm{x} 3.5 \mathrm{~cm}$ ) was always placed on the support side of the FO membrane.

\subsection{FO Bench-scale unit}

A CF042D-FO cell provided by Sterlitech was used in this study. The exterior dimensions of the cell are $12.7 \times 10 \times 8.3 \mathrm{~cm}(5 \times 4 \times 3.25$ in $)$ with a membrane active area of $42 \mathrm{~cm}^{2}\left(6.5 \mathrm{in}^{2}\right)$. CF042D FO cell has a shape of a cube, made of acetal copolymer and can withstand a maximum temperature and pressure of $82^{\circ} \mathrm{C}\left(180^{\circ} \mathrm{F}\right)$ and 1000 psi (69 bar), respectively. The FO system has two stainless steel tanks of $9 \mathrm{~L}$ capacity for the FS and DS supply provided by Sterlitech (USA). The flow rates of the FS and the DS were measured using two panel mount flow meters F-550 from Blue-White industries Ltd. These flow meters have a maximum reading ability up to 4 LPM (1 GPM) and a minimum of 0.4 LPM (0.1 GPM). The flows of the FS and the DS were set in a countercurrent flow mode. The FS and the DS were circulated in the system using two Mount Gear Pumps with Console Drive 115 V PEEK Gears/PTFE seals provided by Sterlitech Company. The maximum motor rotation per minute for the pump is $5000 \mathrm{rpm}$ where the pump can achieve a maximum flow rate of $3200 \mathrm{~mL} / \mathrm{min}$ (3.2 LPM). The pressure of the FS and the DS were measured using pressure gauges type PEM series provided by Winters Company in the range of $0-3$ bar (0 - 45 psi). A MX-CA11B immersion circulator (PolyScience Co-USA) controlled the temperature of the DS during the FO experiments. This controller measured the temperature of solutions which can read up to $135{ }^{\circ} \mathrm{C}$. The conductivity of the FS and the DS were measured by OAKTON PCD650 multi meter. This device has the ability to measure the conductivity, salinity and total dissolved solids (TDS) in the range of 0-500 mS, 0-800 ppt and 0-500 ppt, respectively. Ohaus Ranger ${ }^{\mathrm{TM}}$ bench-scale balance connected to a computer to record the change in the FS weight. Water flux was calculated by measuring the change in weight of the FS over time divided by the membrane area multiplied by water density according to Equation (1):

$J_{w}(L M H)=1000 x \frac{\Delta W}{A t \rho}=\frac{1000\left(W_{f}-W_{i}\right)}{A t \rho}$ Equation (1) 
$174 \Delta \mathrm{W}$ is the change in the FS weight $(\mathrm{kg})$ before and after permeation time, $\mathrm{A}$ is the

175 membrane effective area $\left(\mathrm{m}^{2}\right), t$ is the time $(\mathrm{h})$ and $\rho$ is water density $\left(\mathrm{kg} / \mathrm{m}^{3}\right)$. The initial

176 volume of the DS and the FS were $6 \mathrm{~L}$ and the FS and the DS were recycled back to the

177 same tanks. Figure 1 depicts a schematic diagram of the FO system used in this study.

178

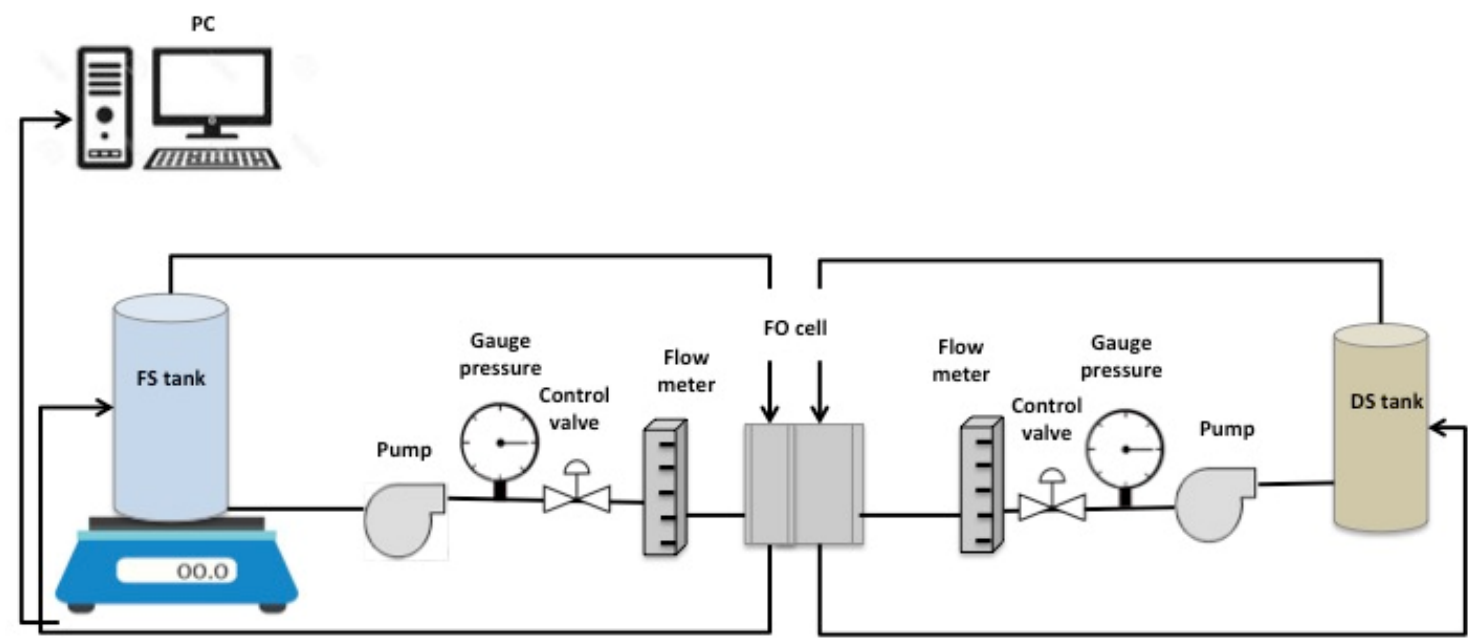

Figure 1. A schematic diagram of the FO system used in this study

\subsection{Experimental procedure}

The experiments were designed to operate for 150 minutes. Firstly, the impact of changing the circulation flow rate of the FS and the DS was studied. Three different flow rates were studied, 0.8:0.8 LPM, 2.0:2.0 LPM, 0.8:2.0 LPM for the draw solution and the feed solution, respectively. Secondly, the influence of increasing the temperature of the DS from $25{ }^{\circ} \mathrm{C}$ to $40{ }^{\circ} \mathrm{C}$ by a $5{ }^{\circ} \mathrm{C}$ increment was studied. Finally, the impact of the membrane orientation was studied where firstlty the membrane active layer (AL) faced the DS (AL-DS), PRO mode and then the membrane AL faced the FS (AL-FS), FO mode. After each run and before the next run the system was washed with distilled water for 30 minutes.

\section{Results and discussion}

\subsection{Impact of Feed Solution (FS) and Draw Solution (DS) flow rates}

\subsubsection{Membrane flux}


193 The impact of increasing the FS flow rate and the DS flow rate on the membrane flux

194 was evaluated at room temperature (i.e. $25^{\circ} \mathrm{C}$ ). The experiments were conducted at a flow

195 rate of 0.8 LPM for the FS and the DS then the flow rates were elevated to 2 LPM for

196 both the FS and the DS. Finally, the membrane flux was evaluated at a FS and DS flow

197 rate of 2.0 and 0.8 LPM, respectively. Each experiment lasted for 150 minutes and the

198 membrane active layer was facing the DS (i.e. PRO mode). Figure 2 (A) shows the

199 change of membrane flux with time at the different flow rates of the FS and the DS.

200 Figure 2 (A) shows the three consecutive runs where the membrane was washed for 30

201 minutes with distilled water between each run. Figure 2 (B) illustrates the average

202 membrane flux in the FO process at the different flow rates of the FS and the DS. In

203 general, membrane flux decreased over time due to the dilution and concentration of

204 draw and feed solution, respectively, that resulted in reducing the osmotic pressure

205 driving force across the FO membrane (Figure 2(A)).

206

(A) 

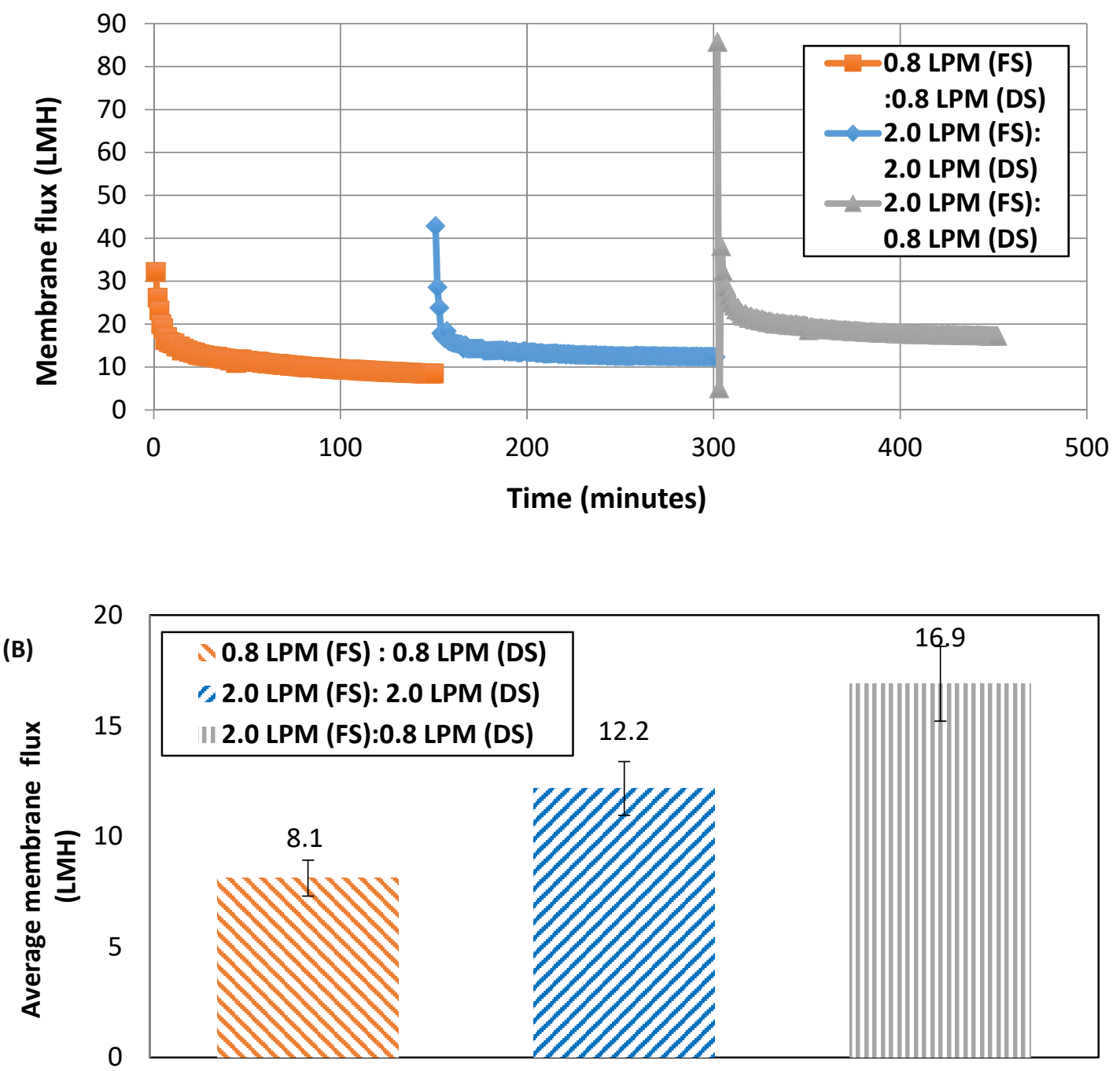

209 Figure 2. (A) Change of membrane flux with time at different FS and DS flow rates (B)

210 The average membrane flux at different FS and DS flow rates at room temperature $\left(25^{\circ} \mathrm{C}\right)$

211 As shown in Figure 2 (A) the membrane flux increased at higher flow rates of the FS and

212 the DS. This is due to increasing the rate of turbulence inside the module which reduces

213 the concentration polarization. The average membrane flux at 0.8 LPM flow rate of FS

214 and DS was $8.1 \mathrm{~L} / \mathrm{m}^{2}$.h, which increased to $12.2 \mathrm{~L} / \mathrm{m}^{2} . h$ at $2.0 \mathrm{LPM}$ flow rate of FS and

215 DS (Figure 2B). This suggests that the high flow rates of FS and DS reduced the effect of

216 concentration polarization and increased the membrane flux [20]. Interestingly, the

217 highest membrane flux was $16.9 \mathrm{~L} / \mathrm{m}^{2} . \mathrm{h}$ at a flow rate of 2.0 LPM for the FS and 0.8

218 LPM for the DS. The reason for the high average membrane flux at these flow rates is

219 due to the development of a small positive hydraulic pressure across the FO membrane in 
220 the same direction of the draw solution. A value of 0.15 bar hydraulic pressure was

221 measured on the feed solution side. This hydraulic pressure was created by the higher

222 flow rate of the FS, 2.0 LPM, compared to FS, 0.8 LPM, inducing an additional

223 permeation flow across the membrane. Increasing the flow rate of the FS and the DS

224 from 0.8 LPM: 0.8 LPM to 2.0 LPM: 2.0 LPM resulted in 33.6\% increase in the average

225 membrane flux while over 52\% increase in the average membrane flux was achieved at

226 2.0:0.8 LPM flow rate of the FS and the DS, respectively. It is apparent that operating the

227 FO system at higher flow rates does not necessarily result in the most desirable

228 membrane flux despite its advantage in reducing the effect of concentration polarization.

229 Operating the FO system at different feeds flow rates with the flow rate of the FS being

230 higher than that of the DS would result in a better membrane flux in the FO process.

231 The drop in the membrane flux over time can be attributed to either the reduction in the

232 osmotic pressure driving force due to the dilution and concentration of the draw and the

233 feed solution as mentioned earlier or it could be due to the fouling of the membrane.

234 Figure 3 shows the Scanning Electron Microscope (SEM) images for the active and

235 support layer of the FO membrane before and after the FO experiments. Figure 3 (A) and

236 Figure 3 (B) show the clean (i.e. before use) active layer and support layer of the

237 membrane, respectively. Figure 3 (C) and Figure 3 (D) show the membrane active layer

238 and support layer, respectively, after the experimental run and before washing the

239 membrane with distilled water. Figure $3(\mathrm{E})$ and Figure $3(\mathrm{~F})$ show the membrane active

240 layer and support layer, respectively, after washing the membrane with distilled water for

24130 minutes. It is clear from Figure 3 (C) and Figure 3(D) that salts accumulated on both

242 sides of the membrane forming a fouling layer on the membrane surface. However, it

243 should be noted that the same membrane was used for three consecutive runs. The

244 membrane was washed after every experiment for 30 minutes with distilled water. In fact,

245 all tests were repeated three times and the membrane flux results were very close in all

246 runs after membrane washing. This indicates that the fouling materials were washed out

247 during the washing process. Figure 3 (E) and Figure 3 (F) show the membrane active

248 layer and support layer were clean after washing with distilled water for 30 minutes.

249 Generally, fouling of the FO membrane seems to be reversible by membrane cleaning 
250 with distilled water. This finding is in an agreement with previous work carried out by

251 Modern Water in Oman [9]

252

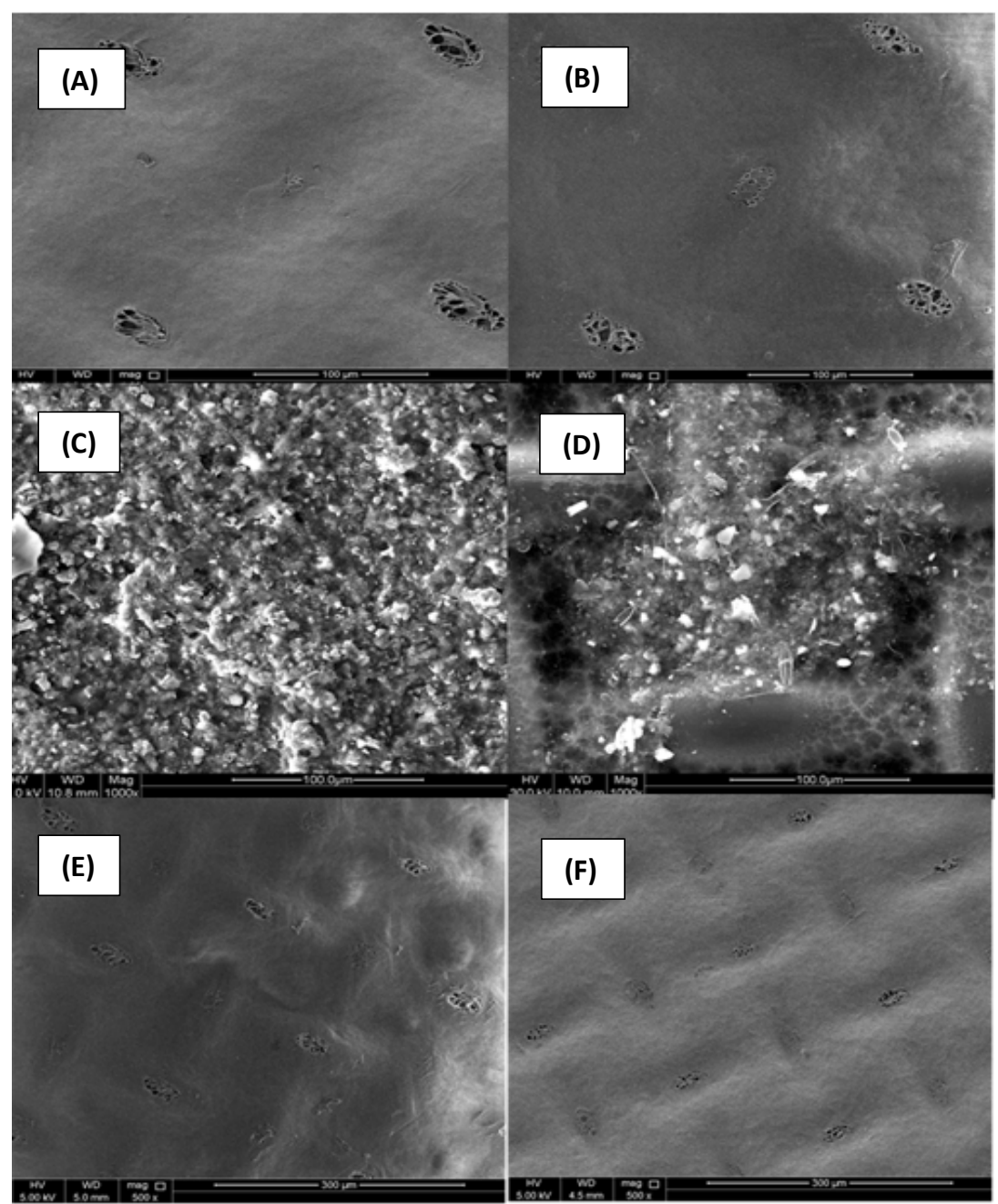

Figure 3. Fouling on the FO membrane surface after permeation during PRO mode (A) clean active layer, (B) clean support layer, (C) active layer after use, (D) support layer after use, (E) active layer after washing with distilled water for 30 minutes, (F) support layer after washing with distilled water for 30 minutes.

\subsubsection{Recovery rate}

256 Figure 4 shows the achieved recovery rates at the studied flow rates after 150 minutes.

257 The recovery rate percentage is calculated using Equation (2) [39]: 
$259 \% \mathrm{R}=\frac{\frac{\Delta \mathrm{V}_{\mathrm{p}}}{\Delta \mathrm{t}}}{\frac{\Delta \mathrm{V}_{\mathrm{F}}}{\Delta \mathrm{t}}} 100$

Equation (2)

$260 \Delta \mathrm{V}_{\mathrm{p}}$ and $\Delta \mathrm{V}_{\mathrm{F}}$ are the change in volume of permeate and feed solution (L), respectively,

261 and $\Delta \mathrm{t}$ is time of the experiment (h). Equation 2 can be described in terms of $V_{p}$ and $V_{F}$

262 since $\Delta \mathrm{t}$ is equal for both permeate and feed solution:

263

$264 \% \mathrm{R}=\frac{\mathrm{V}_{p}}{\mathrm{~V}_{\mathrm{F}}} \times 100 \%$

Equation (3)

$265 V_{p}$ is the permeate volume at the end of each run and $V_{F}$ is the initial volume of the feed

266 solution. The maximum recovery rate at 0.8:0.8 LPM flow rate of the feed and the draw

267 solution was $1.4 \%$, increased to $2.1 \%$ at 2.0:2.0 LPM flow rate of the feed and the draw

268 solution. The maximum recovery rate of 3\% was achieved at 2.0 LPM: 0.8 LPM flow

269 rate of the feed and the draw solution, respectively. As explained earlier the higher

270 recovery rate at 2.0 LPM: 0.8 LPM was due to the development of a positive hydraulic

271 pressure in the same direction of the draw solution, which promoted further permeation

272 flow across the membrane.

273

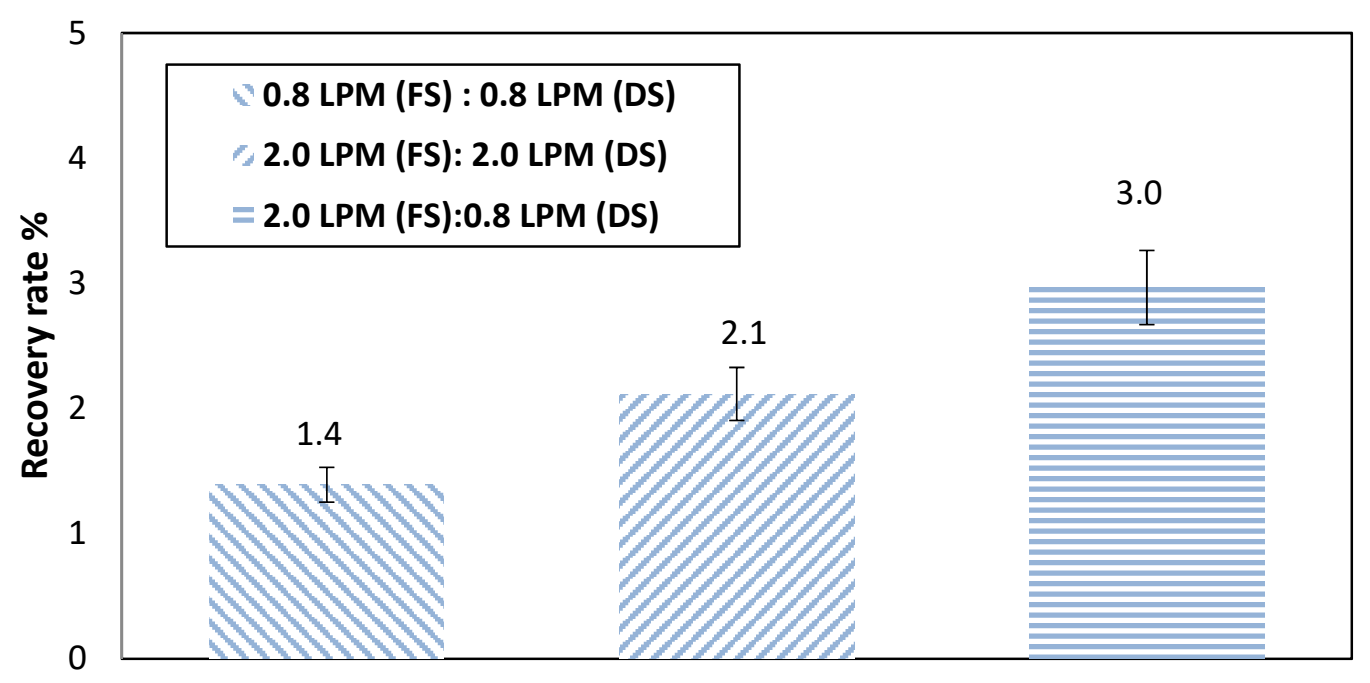

274 Figure 4. Impact of increasing FS and DS flow rates on recovery rate percentage at 275 isothermal conditions $\left(25^{\circ} \mathrm{C}\right)$. 
278 The concentration of $\mathrm{Ca}^{2+}, \mathrm{Mg}^{2+}$ and $\mathrm{SO}_{4}{ }^{2-}$ ions were measured in the DS before and after

279 the experimental runs. As mentioned earlier, these ions are responsible for scale

280 formation and deposition in the MSF desalination plant. As shown in Table 2 at 0.8 LPM:

2810.8 LPM flow rate of the feed solution and the draw solution and at room temperature,

282 the concentration of $\mathrm{SO}_{4}{ }^{2-}, \mathrm{Mg}^{2+}$, and $\mathrm{Ca}^{2+}$ ions in the draw solution was 5203.9, 2539.8

283 and $733.6 \mathrm{ppm}$, respectively. After the FO experimental run these concentrations became

$2845163.3,2519.9$ and $714.1 \mathrm{ppm}$ for $\mathrm{SO}_{4}{ }^{2-}, \mathrm{Mg}^{2+}$ and $\mathrm{Ca}^{2+}$ ions, respectively. It was noticed

285 that the draw solution was diluted by $0.78 \%, 0.78 \%$ and $1.1 \%$ for $\mathrm{SO}_{4}^{2-}, \mathrm{Mg}^{2+}$, and $\mathrm{Ca}^{2+}$

286 ions, respectively. The corresponding dilution in ions concentration at 2.0:2.0 LPM flow

287 rate of the feed solution and the draw solution was $2.6 \%, 1.3 \%$ and $1.7 \%$ for $\mathrm{SO}_{4}{ }^{2-}, \mathrm{Mg}^{2+}$

288 and $\mathrm{Ca}^{2+}$ ions, respectively. Where the concentration of $\mathrm{SO}_{4}{ }^{2-}, \mathrm{Mg}^{2+}$ and $\mathrm{Ca}^{2+}$ ions in the

289 draw solution was 5052.9, 2493.7 and 729 ppm, respectively. After the FO experimental

290 run these concentrations became 4923.4, 2460.9 and $716.8 \mathrm{ppm}$ for $\mathrm{SO}_{4}{ }^{2-}, \mathrm{Mg}^{2+}$ and $\mathrm{Ca}^{2+}$

291 ions, respectively. A further dilution of $2.9 \%, 1.8 \%$ and $2.2 \%$ for $\mathrm{SO}_{4}{ }^{2-}, \mathrm{Mg}^{2+}$ and $\mathrm{Ca}^{2+}$

292 ions, respectively was achieved at 2.0:0.8 LPM flow rate of the feed solution and the

293 draw solution. Where the concentration of $\mathrm{SO}_{4}{ }^{2-}, \mathrm{Mg}^{2+}$ and $\mathrm{Ca}^{2+}$ ions in the draw solution

294 was 5712.2, 2601.6 and 726.2 ppm, respectively. After the FO experimental run these

295 concentrations became 5547.6, 2555.3 and $715.5 \mathrm{ppm}$ for $\mathrm{SO}_{4}^{2-}, \mathrm{Mg}^{2+}$ and $\mathrm{Ca}^{2+}$ ions,

296 respectively. It was noticed that the $\mathrm{SO}_{4}{ }^{2-}$ and $\mathrm{Ca}^{2+}$ ions exhibited higher dilution

297 percentage than the $\mathrm{Mg}^{2+}$ ions; this was attributed to several factors such as the FO

298 membrane rejection to ions and to the ions diffusion coefficient. Generally, $\mathrm{SO}_{4}{ }^{2-}$ is

299 highly rejected by FO membranes because of its negative charge and its large molecular

300 weight $[10,18]$. FO membrane rejection to $\mathrm{Ca}^{2+}$ was higher than $\mathrm{Mg}^{2+}$ because of the

301 larger molecular weight of calcium ions compared to magnesium ions. It should be also

302 noted that $\mathrm{SO}_{4}{ }^{2-}$ has a diffusion coefficient of $1.07 * 10^{-9} \mathrm{~m}^{2} / \mathrm{s}$, which is higher than that of

$303 \mathrm{Ca}^{2+}$ (i.e. $0.793 * 10^{-9} \mathrm{~m}^{2} / \mathrm{s}$ ) and $\mathrm{Mg}^{+2}$ (i.e. $0.703 * 10^{-9} \mathrm{~m}^{2} / \mathrm{s}$ ). This will affect ions reverse

304 salt diffusion across the membrane and hence concentration in solution. A high rejection

305 of $\mathrm{SO}_{4}{ }^{2-}$ ions by $\mathrm{FO}$ membranes is very important in the FO pretreatment of seawater to

306 prevent scale formation in the MSF plant since $\mathrm{MgSO}_{4}$ and $\mathrm{CaSO}_{4}$ are the main non-

307 alkaline scale formations. It should be mentioned here that the initial concentrations of 
317 Table 2: Concentration of $\mathrm{SO}_{4}{ }^{2-}, \mathrm{Mg}^{2+}$, and $\mathrm{Ca}^{2+}$ ions in the DS before and after the $\mathrm{FO}$ 318 experiments at different DS and FS flowrates and at room temperature.

\begin{tabular}{|c|c|c|c|c|c|}
\hline $\begin{array}{c}\text { Ion } \\
(\mathbf{p p m})\end{array}$ & $\begin{array}{l}\text { Flow rates of } \\
\text { FS and DS } \\
\text { (LPM) }\end{array}$ & $\begin{array}{c}\text { Initial ions } \\
\text { concentration } \\
\text { in DS } \\
(\text { ppm) }\end{array}$ & $\begin{array}{c}\text { Ions } \\
\text { concentration } \\
\text { in DS at the } \\
\text { end of the run } \\
\text { (ppm) }\end{array}$ & $\begin{array}{c}\text { Reduction } \\
\text { (ppm) }\end{array}$ & $\begin{array}{c}\text { Reduction } \\
(\%)\end{array}$ \\
\hline \multirow[t]{3}{*}{$\mathrm{SO}_{4}{ }^{2-}$} & $\begin{array}{l}0.8 \text { LPM (FS): } \\
0.8 \text { LPM (DS) }\end{array}$ & 5203.9 & 5163.3 & 40.6 & 0.78 \\
\hline & $\begin{array}{l}\text { 2.0 LPM (FS): } \\
\text { 2.0 LPM (DS) }\end{array}$ & 5052.9 & 4923.4 & 129.5 & 2.6 \\
\hline & $\begin{array}{l}\text { 2.0 LPM (FS): } \\
0.8 \text { LPM (DS) }\end{array}$ & 5712.2 & 5547.6 & 164.6 & 2.9 \\
\hline \multirow[t]{3}{*}{$\mathrm{Mg}^{2+}$} & $\begin{array}{l}0.8 \text { LPM (FS): } \\
0.8 \text { LPM (DS) }\end{array}$ & 2539.8 & 2519.9 & 19.9 & 0.78 \\
\hline & $\begin{array}{l}\text { 2.0 LPM (FS): } \\
\text { 2.0 LPM (DS) }\end{array}$ & 2493.7 & 2460.9 & 32.8 & 1.3 \\
\hline & $\begin{array}{l}2.0 \text { LPM (FS): } \\
0.8 \text { LPM (DS) }\end{array}$ & 2601.6 & 2555.3 & 46.3 & 1.8 \\
\hline \multirow[t]{3}{*}{$\mathrm{Ca}^{2+}$} & $\begin{array}{l}0.8 \text { LPM (FS): } \\
0.8 \text { LPM (DS) }\end{array}$ & 733.6 & 714.1 & 8.06 & 1.1 \\
\hline & $\begin{array}{l}\text { 2.0 LPM (FS): } \\
\text { 2.0 LPM (DS) }\end{array}$ & 729 & 716.8 & 12.2 & 1.7 \\
\hline & $\begin{array}{l}2.0 \text { LPM (FS): } \\
0.8 \text { LPM (DS) }\end{array}$ & 726.2 & 715.5 & 16.1 & 2.2 \\
\hline
\end{tabular}


321 Practically, the temperature of brine reject from an MSF desalination plant will be around

$32240^{\circ} \mathrm{C}$. Therefore, we investigated the impact of the draw solution temperature on the

323 performance of the FO process. Increasing the temperature of the draw solution was

324 evaluated at different flow rates of the feed and the draw solutions. The experiments were

325 conducted at draw solution temperatures of $25^{\circ} \mathrm{C}, 30^{\circ} \mathrm{C}, 35^{\circ} \mathrm{C}$, and $40^{\circ} \mathrm{C}$ while the

326 temperature of the feed solution remained constant at $25^{\circ} \mathrm{C}$. Typically, the temperature of

327 MSF brine is about $40^{\circ} \mathrm{C}$ but using different brine temperature would help to understand

328 the impact of DS temperature on the performance of the FO process. The duration of each

329 experiment was 150 minutes in which the membrane active layer was facing the DS (i.e.

330 PRO mode). Figure 5 (A) presents the average membrane flux at the different draw

331 solution temperatures and flow rates of feed and draw solutions. It was noticed that for

332 any given flow rates, the average membrane flux increased with the increase in the

333 temperature of the draw solution from $25^{\circ} \mathrm{C}$ to $40^{\circ} \mathrm{C}$. At $0.8: 0.8$ flow rate of the feed and

334 the draw solution, the average membrane flux was $8.1 \mathrm{~L} / \mathrm{m}^{2} . h$ at a DS temperature of

$33525^{\circ} \mathrm{C}$ which increased to $13.9 \mathrm{~L} / \mathrm{m}^{2}$.h at a DS temperature of $40^{\circ} \mathrm{C}$, achieving $72 \%$ higher

336 average membrane flux due to the temperature increase of the DS. The corresponding

337 increase in the average membrane flux for 2.0 LPM: 2.0 LPM and 2.0 LPM: 0.8 LPM

338 flow rates for the FS and the DS was $52 \%$ and $32 \%$, respectively. The increase of the

339 membrane flux at high draw solution temperature could be due to the lower water

340 viscosity and greater diffusivity across the membrane at higher temperatures.

341 Furthermore, according to Van't Hoff equation, the osmotic pressure increases with the

342 increase of the draw solution temperature, therefore, the driving force in the process

343 increases. Figure 5(A) also shows that the impact of feeds' flow rates on the average

344 membrane flux remained unaffected with the variation in the temperature of the feed

345 solution. The FO process at flow rate equal to 2.0 LPM: 0.8 LPM for the feed solution

346 and the draw solution, respectively, exhibited the highest average membrane flux, which

347 reached $22.3 \mathrm{~L} / \mathrm{m}^{2} . \mathrm{h}$ at $40^{\circ} \mathrm{C}$. According to a previous study by Hawari et al. [21], the

348 membrane flux in a FO process increased with increasing the draw solution temperature.

349 The membrane flux reached a maximum value at a draw solution temperature around 26

$350{ }^{\circ} \mathrm{C}$ before it started to decrease again with further temperature increase of the draw 
351 solution up to $32^{\circ} \mathrm{C}$. On the contrary, the membrane flux in this study kept increasing as

352 the temperature of the DS increased. Where at the highest draw solution temperature of

$35340^{\circ} \mathrm{C}$ the highest membrane flux was obtained. This could be due to the increase of the

354 flow rates of the feed solution and the draw solution that resulted in i) reducing the

355 impact of concentration polarization which could have overcame the thermal-osmosis

356 effect ii) developing a positive hydraulic pressure across the FO membrane that promoted

357 permeation flow. Where at flow rates 2.0 LPM for FS and 0.8 LPM of DS a 0.15 bar

358 hydraulic pressure was measured across the membrane. This can be clearly seen in Figure

3595 (A) where at the flow rates of 0.8 LPM: 0.8 LPM for the FS and DS there was no

360 enhancement in the membrane flux when the temperature increased from $35^{\circ} \mathrm{C}$ to $40^{\circ} \mathrm{C}$.

361 In effect, the effect of CP decreased at high flow rates of the feed and draw solution,

362 leading to a noticeable increase in the water flux from the feed to draw solution which

363 reduced the counter water flux due to the thermal-osmosis. It should be noted that the

364 obtained average membrane flux was found to be very promising and it is 2.3 to 5.5 times

365 more than the theoretically anticipated water flux in previous studies [22-26]. However,

366 water flux between 25 and $33 \mathrm{~L} / \mathrm{m} 2 \mathrm{~h}$ was reported in $\mathrm{FO}$ experiments treating feed water

367 at $32 \mathrm{oC}[20]$. Figure 5B also show that, depending on the temperature of draw solution,

368 increasing the flow rate of feed solution from 0.8 LPM to 2.0 LPM resulted in 33 to

$369100 \%$ increase in water flux. On the other hand, increasing the temperature of draw

370 solution (using same flow rates) resulted in up to $71 \%$ increase in water flux. As such,

371 increasing flow rate of feed solution resulted in a larger improvement in the water flux.

372

373 


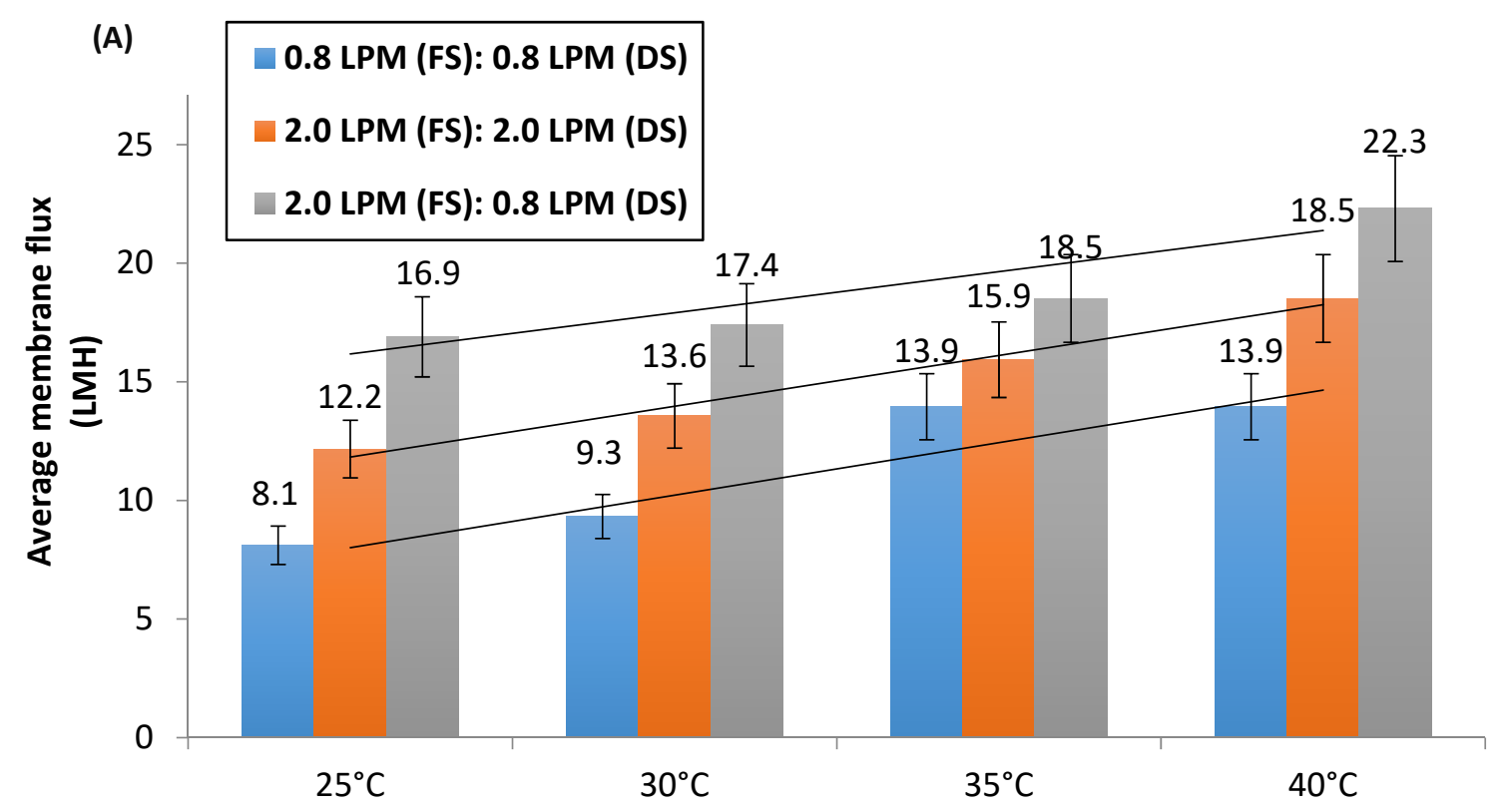

374

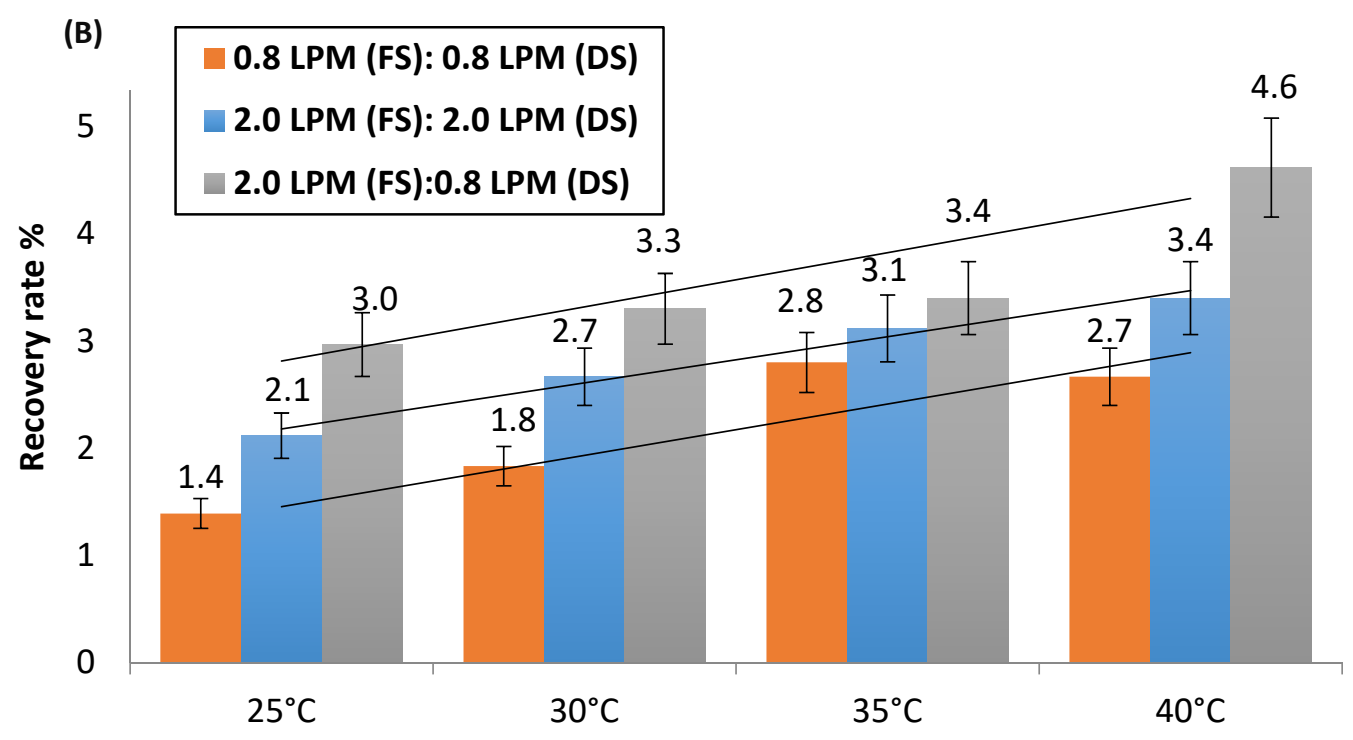

376 Figure 5. (A) Average membrane flux at different DS temperatures for the different 377 studied flow rates (B) Water recovery percentage at different DS temperature for the 378 different studied flow rates

379 Figure 5 (B) shows the recovery rate of the FO process at different flow rates of the draw 380 solution and the feed solution. The recovery rate of the FO process increased with 381 increasing the temperature of the draw solution from $25^{\circ} \mathrm{C}$ to $40^{\circ} \mathrm{C}$ and was always higher 382 at 2.0:0.8 LPM flow rate of the feed and the draw solution. At the 2.0:0.8 LPM flow rate, 

the recovery rated increased by $35 \%$, from $3 \%$ to $4.6 \%$, due to the increase of DS temperature from $25^{\circ} \mathrm{C}$ to $40^{\circ} \mathrm{C}$. The reason for a greater membrane flux at a draw solution temperature of $40^{\circ} \mathrm{C}$ is due to the higher diffusivity of water molecules at elevated temperatures and higher osmotic pressure of draw solution. The FO process resulted in $2.9 \%, 1.8 \%$ and $2.2 \%$ dilution of $\mathrm{SO}_{4}{ }^{2-}, \mathrm{Mg}^{2+}$, and $\mathrm{Ca}^{2+}$ ions in the draw solution, respectively at $25^{\circ} \mathrm{C}$ and 2.0:0.8 LPM flow rate. The dilution of $\mathrm{SO}_{4}{ }^{2-}, \mathrm{Mg}^{2+}$, and $\mathrm{Ca}^{2+}$ ions in the draw solution increased to $7.7 \%, 4.9 \%$, and $8.5 \%$, respectively at $40^{\circ} \mathrm{C}$ and 2.0:0.8 LPM flow rate. As indicated before, $\mathrm{SO}_{4}{ }^{2-}$ and $\mathrm{Ca}^{2+}$ ions exhibited higher dilution by the $\mathrm{FO}$ than $\mathrm{Mg}^{2+}$ ion but most important that $\mathrm{SO}_{4}{ }^{2-}$ ions are reduced in the solution since it is the main component in non-alkaline scale formations in the MSF plant.

\subsection{Impact of membrane orientation}

The membrane orientation is one of the factors that would affect the performance of the FO process [20]. The membrane flux was evaluated in the PRO mode (DS-AL) and in the FO mode (FS-AL). Figure 6 shows that the membrane flux was generally higher in the PRO mode than in the FO mode. This is due to the lower effect of concentration polarization in the PRO mode. This is in agreement with previous studies, which demonstrated better controllable concentration polarization effects when the FO process operates in the PRO mode [20,27-29]. Figure 6 shows that the average membrane flux in the FO mode was equal to that in the PRO mode at low flow rates, i.e. 0.8:0.8 LPM, and feed temperatures $30^{\circ} \mathrm{C}$ to $40^{\circ} \mathrm{C}$. Whilst the average membrane flux in the PRO mode was higher than that in the FO mode at 2.0:2.0 LPM and 2.0:0.8 LPM. This suggest that at low feeds' flow rates, the FO process has no preference to operate on either mode, i.e. FO or PRO, whereas at high feeds' flow rate it is desirable to operate the process at the PRO mode to increase the membrane flux. In case of seawater contains high fouling materials, it is suggested to operate the process in the FO mode and hence 0.8:0.8 LPM would be more energy-efficient and easier to clean the membrane. However, 2.0:0.8 LPM FO process operating at the PRO mode generated 1.6 times more water flux than 0.8:0.8 LPM FO process and should be considered when seawater quality does not promote membrane fouling. 


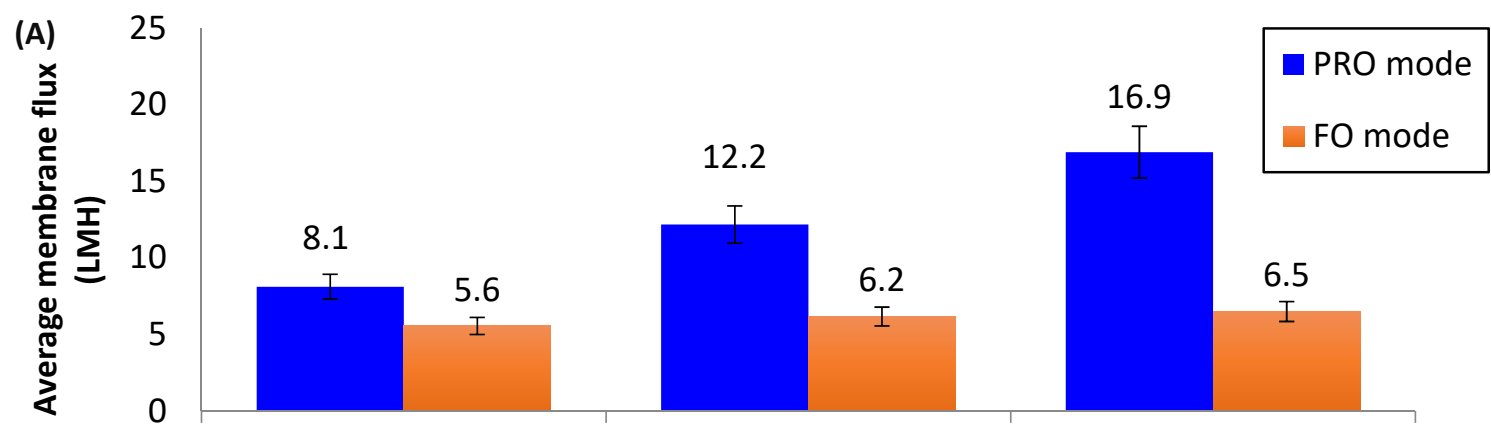

(B)
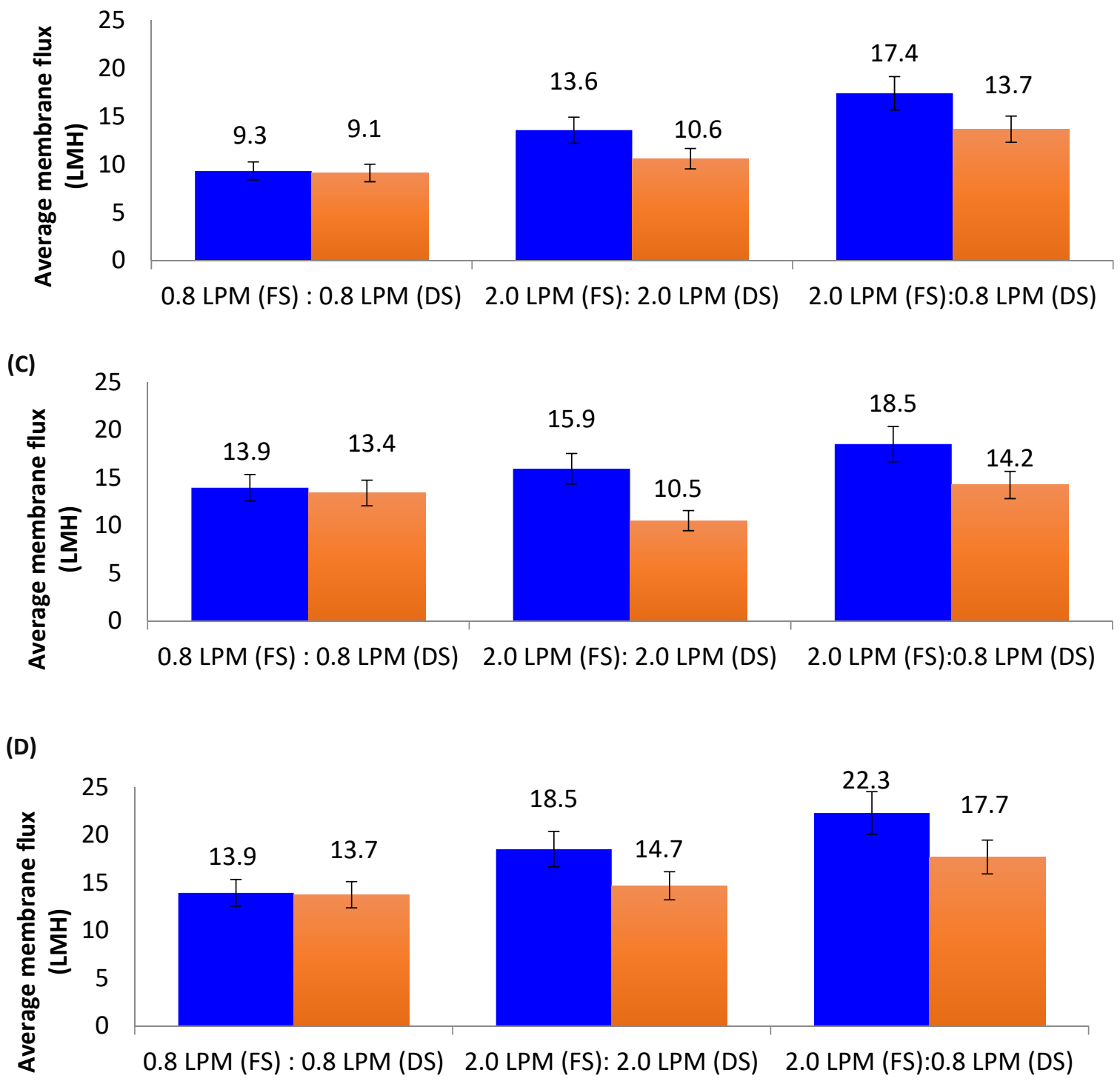

Figure 6. Impact of membrane orientation on average membrane flux (A. At DS temperature of $25^{\circ} \mathrm{C}$, B. At DS temperature of $30^{\circ} \mathrm{C}$, C. At DS temperature of $35^{\circ} \mathrm{C}$, D. At DS temperature of $40^{\circ} \mathrm{C}$ ) 


\section{Conclusions}

416 The feasibility of employing the forward osmosis (FO) process in the pretreatment of

417 Multi Stage Flashing (MSF) desalination plant feed solution was evaluated in the present

418 study. Brine reject from real MSF desalination plant and seawater were the draw and feed

419 solutions. The impact of increasing the FS flow rate and the DS flow rate on the

420 membrane flux was evaluated. It was found that the highest membrane flux was 16.9

$421 \mathrm{~L} / \mathrm{m}^{2}$.h at a flow rate of 2.0 LPM for the FS and 0.8 LPM for the DS. The maximum

422 membrane flux was $22.3 \mathrm{~L} / \mathrm{m}^{2}$.h at $40^{\circ} \mathrm{C}$ draw solution temperature, this actually three

423 times more than the theoretical flux expected in the previous studies that suggested FO

424 process for treatment of feed solution to the MSF. The study showed that water flux was

425 generally higher in the PRO mode than in the FO mode. In fact, this is not a problem in

426 the FO process for seawater pretreatment for the MSF desalination plant since results

427 demonstrated that the membrane flux can be fully recovered by washing the membrane

428 with distilled water for 30 minutes. This indicates that the fouling was not severe and

429 mainly reversible. In general, the study showed the promising application of FO process

430 for pretreatment of seawater to MSF plant. A pilot plant test is planned to take place in

431 the very near future.

\section{Acknowledgments}

434 This research is made possible by NPRP award (NPRP10-0117-170176) from Qatar

435 National Research Fund (QNRF). The statements made herein are solely the

436 responsibility of the authors. In addition, the authors wish to thank Qatar Foundation for

437 the financial support provided to one of the co-authors through a graduate sponsorship

438 research award (GSRA4-2-0402-17013). The authors also wish to thank Qatar Electricity

439 and Water Company (QEWC) for the supply of brine.

440 References

441 1. Budhiraja P, Fares AA. Studies of scale formation and optimization of antiscalant 442 dosing in multi-effect thermal desalination units. Desalination. 2008;220(1-3):31344325 .

444 2. Ghani S, Al-Deffeeri NS. Impacts of different antiscalant dosing rates and their 
thermal performance in Multi Stage Flash (MSF) distiller in Kuwait. Desalination [Internet]. 2010;250(1):463-72. Available from: http://dx.doi.org/10.1016/j.desal.2009.09.077

3. El Din AMS, Mohammed RA. Brine and scale chemistry in MSF distillers. Desalination. 1994; 99(1):73-111.

4. Hamed OA, Al-Otaibi HA. Prospects of operation of MSF desalination plants at high TBT and low antiscalant dosing rate. Desalination [Internet]. 2010;256(13):181-9. Available from: http://dx.doi.org/10.1016/j.desal.2010.01.004

5. Tijing LD, Woo YC, Choi JS, Lee S, Kim SH, Shon HK. Fouling and its control in membrane distillation-A review. J Memb Sci [Internet]. 2015;475:215-44. Available from: http://dx.doi.org/10.1016/j.memsci.2014.09.042

6. Amjad Z. Calcium sulfate dihydrate (gypsum) scale formation on heat exchanger surfaces: The influence of scale inhibitors. J Colloid Interface Sci. 1988;123(2):52336.

7. Lyster E, Kim M man, Au J, Cohen Y. A method for evaluating antiscalant retardation of crystal nucleation and growth on RO membranes. J Memb Sci [Internet]. 2010;364(1-2):122-31. Available from: http://dx.doi.org/10.1016/j.memsci.2010.08.020

8. Warsinger DM, Swaminathan J, Guillen-Burrieza E, Arafat HA, Lienhard V JH. Scaling and fouling in membrane distillation for desalination applications: A review. Desalination [Internet]. 2015;356:294-313. Available from: http://dx.doi.org/10.1016/j.desal.2014.06.031

9. Nicoll PG. Forward osmosis as a pre-treatment to reverse osmosis. Int Desalin Assoc World Congr Desalin Water Reuse 2013 [Internet]. 2013;1-21. Available from: http://www.modernwater.com/assets/downloads/Papers/Forward Osmosis as a Pretreatment to Reverse Osmosis.pdf

10. Hassan AM, Al-Sofi MAK, Al-Amoudi AS, Jamaluddin ATM, Farooque AM, Rowaili A, et al. A new approach to membrane and thermal seawater desalination processes using nanofiltration membranes (Part 1). Desalination. 1998;118(13):35-51.

11. Abdel Nasser Mabrouk, Hassan Fath MD and HA. Techno-Economics of Hybrid NF / FO with Thermal Desalination Plants. World's largest Science, Technology \& Medicine Open Access book publisher. 2015 p.

12. Eriksson P, Kyburz M, Pergande W. NF membrane characteristics and evaluation for sea water processing applications. Desalination. 2005;184(1-3):281-94.

13. Mezher T, Fath H, Abbas Z, Khaled A. Techno-economic assessment and environmental impacts of desalination technologies. Desalination. 2011;266(13):263-73.

14. Altaee A. Forward Osmosis : Potential use in Desalination and Water Reuse. J Membr Sep Technol. 2012;1(Md):79-93.

15. Altaee A, Mabrouk A, Bourouni K, Palenzuela P. Forward osmosis pretreatment of seawater to thermal desalination: High temperature FO-MSF/MED hybrid system. Desalination [Internet]. 2014;339(1):18-25. Available from: http://dx.doi.org/10.1016/j.desal.2014.02.006

16. Petty JD, Huckins JN, David A. (12) Patent Application Publication (10) Pub . No $\therefore$ US 2002/0187020 A1. 2002;1(19). 
17. Altaee A, Mabrouk A, Bourouni K. A novel Forward osmosis membrane pretreatment of seawater for thermal desalination processes. Desalination [Internet]. 2013;326:19-29. Available from: http://dx.doi.org/10.1016/j.desal.2013.07.008

18. Hassan AM. Review of Development of the New Nf-Seawater Desalination Process From Pilot Plant To. Engineering. 2002;2(December):14-7.

19. Torrey S, Scott J. Membrane and ultrafiltration technology: developments since 1981 [Internet]. Noyes Data Corp.; 1984. (Chemical technology review). Available from: https://books.google.com.qa/books?id=JoA3AQAAIAAJ

20. Hawari AH, Kamal N, Altaee A. Combined influence of temperature and flow rate of feeds on the performance of forward osmosis. Desalination. 2016;398:98-105.

21. Mengual JI, García López F, Fernández-Pineda C. Permeation and thermal osmosis of water through cellulose acetate membranes. J Memb Sci. 1986;26(2):211-30.

22. Wilke CRC. A.I.Ch.E.J. 1955;

23. Phuntsho S, Vigneswaran S, Kandasamy J, Hong S, Lee S, Shon HK. Influence of temperature and temperature difference in the performance of forward osmosis desalination process. J Memb Sci [Internet]. 2012;415-416:734-44. Available from: http://dx.doi.org/10.1016/j.memsci.2012.05.065

24. Zhao P, Gao B, Yue Q, Liu S, Shon HK. Effect of high salinity on the performance of forward osmosis: Water flux, membrane scaling and removal efficiency. Desalination [Internet]. 2016;378:67-73. Available from: http://dx.doi.org/10.1016/j.desal.2015.09.028

25. Xie M, Price WE, Nghiem LD, Elimelech M. Effects of feed and draw solution temperature and transmembrane temperature difference on the rejection of trace organic contaminants by forward osmosis. J Memb Sci. 2013;438:57-64.

26. Zhao S, Zou L. Effects of working temperature on separation performance, membrane scaling and cleaning in forward osmosis desalination. Desalination [Internet]. 2011;278(1-3):157-64. Available from: http://dx.doi.org/10.1016/j.desal.2011.05.018

27. Gray GT, McCutcheon JR, Elimelech M. Internal concentration polarization in forward osmosis: role of membrane orientation. Desalination. 2006;197(1-3):1-8.

28. Tang CY, She Q, Lay WCL, Wang R, Fane AG. Coupled effects of internal concentration polarization and fouling on flux behavior of forward osmosis membranes during humic acid filtration. J Memb Sci [Internet]. 2010;354(12):123-33. Available from: http://dx.doi.org/10.1016/j.memsci.2010.02.059

29. Xu Y, Peng X, Tang CY, Fu QS, Nie S. Effect of draw solution concentration and operating conditions on forward osmosis and pressure retarded osmosis performance in a spiral wound module. J Memb Sci. 2010;348(1-2):298-309. 